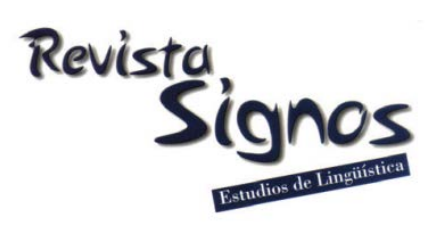

\title{
Recontextualización del conocimiento en textos escolares chilenos*
}

\section{Recontextualization of knowledge in Chilean textbooks}

\author{
Romualdo Ibáñez \\ PONTIFICIA UNIVERSIDAd CATÓLICA DE \\ VALParaíso \\ CHILE \\ romualdo.ibanez@pucv.cl
}

\author{
Fernando Moncada \\ Pontificia Universidad Católica de \\ VALPARAÍSO \\ CHILE \\ fernandomoncada.n@gmail.com
}

\author{
Valeria Arriaza \\ PONTIFICIA UNIVERSIDAd CATÓliCA DE \\ VALPARAÍsO \\ CHILE \\ valeria.arriaza.p@gmail.com
}

Recibido: 25-IX-2017 / Aceptado: 10-V-2018

\section{Resumen}

El objetivo del presente estudio fue caracterizar el proceso de recontextualización del conocimiento (Bernstein, 1990) a partir de las funciones que cumplen Géneros del Conocimiento (GCOs) en textos escolares de Educación Básica, utilizados en Chile. Para ello, mediante un enfoque descendente-ascendente (Biber, Connor \& Upton, 2007) se analizó un corpus constituido por las 11,139 instancias de los 15 GCOs identificados por Ibáñez, Moncada, Cornejo y Arriaza (2017). El análisis reveló la existencia de 11 funciones que pueden ser desempeñadas por los GCOs en el Texto Escolar (TE). Se constató, además, que existen funciones que son realizadas en más de un GCO y que algunos GCOs desempeñan más de una función en el TE. A partir de estos resultados, se concluye que la recontextualización también se puede evidenciar en las funciones que cumplen los GCOs en el TE y que estas varían entre las asignaturas.

Palabras Clave: Recontextualización, Géneros del Conocimiento, Texto Escolar, funciones, discurso pedagógico. 


\begin{abstract}
This study aimed to characterize the process of knowledge recontextualization (Bernstein, 1990) based on the functions that Knowledge Genres perform in elementary school textbooks, used in Chile. The analysis was conducted on a corpus comprising the 11,139 instances of the 15 Knowledge Genres reported by Ibáñez, Moncada, Cornejo and Arriaza (2017), adopting a top-down bottom-up approach (Biber, Connor \& Upton, 2007). Our results reveal 11 functions that can be performed by Knowledge Genres in school textbooks. Additionally, it was observed that some functions are realized in one or more Knowledge Genres and, also, that some Knowledge Genres perform two functions. Based on these results, it can be concluded that recontextualization can also be observed in the functions that Knowledge Genres perform in school textbooks and that such functions vary across subjects.
\end{abstract}

Key Words: Recontextualization, Knowledge Genres, School Textbook, functions, pedagogic discourse.

\title{
INTRODUCCIÓN
}

Como fenómeno de orden comunicativo, la recontextualización constituye un proceso de transformación desde el contexto primario de producción hacia un contexto secundario, lo que implica, en muchos casos, modificaciones en términos de selección, simplificación, condensación, o refocalización de los textos (Bernstein, 1990; Christie, 2002). Según Bernstein (1990), este proceso transformativo tiene lugar, debido a la necesidad social de enseñar, es decir, de transferir el conocimiento desde el contexto en el que es producido hasta un contexto pedagógico, en el que es diseminado y reproducido.

Dado que la recontextualización constituye un eslabón fundamental entre el proceso de generación del conocimiento y su comunicación, permea prácticamente toda la actividad educativa, desde la selección de los contenidos a incorporar en el currículum nacional, hasta su uso en el aula. En contextos escolares, la recontextualización es observable en diferentes géneros pedagógicos, tales como guías didácticas, reseñas o mapas. Entre ellos, uno que destaca es el Texto Escolar (TE) (Choppin, 1998). De hecho, y dada su relevancia en la actividad pedagógica, es posible sostener que se trata del género discursivo a través del cual se recontextualiza la mayor parte del conocimiento generado en las diferentes áreas del saber. Conscientes de la relevancia de este género en la comunicación del conocimiento, especialistas en el estudio del lenguaje y la educación han comenzado a estudiarlo desde diferentes perspectivas (Achugar \& Schleppegrell, 2005; Moss, 2009; Barletta \& Chamorro, 2011; Chamorro, Mizuno \& Moss, 2011; Pinuer \& Oteíza, 2016; Ávila, Barletta \& Chamorro, 2017). Asimismo, en el contexto investigativo chileno, se han llevado a cabo numerosos estudios, los que han indagado en variadas temáticas como el análisis de contenidos (Olivares, 2007; Tamayo, 2007; Zúñiga, 2007; Riedemann, 2010; DíazLevicoy \& Cezón, 2017), el componente ideológico (Oteíza, 2009a, 2009b; Fernández, 
2010; Espinoza, 2012; Leyton, Ávalos \& Calderón, 2018), las relaciones entre modos semióticos (Pereira \& González, 2011; Oteíza \& Pinuer, 2016), la intertextualidad (Oteíza, 2014) o las oportunidades de aprendizaje y habilidades científicas promovidas en el TE (Ruiz, Meneses \& Montenegro, 2014; Meneses, Montenegro \& Ruiz, 2014; Ruiz, Montenegro, Meneses \& Venegas, 2016).

Entre estas temáticas, una de particular interés para este trabajo, es la configuración discursiva del TE. Un estudio reciente de este tipo es en el que Ibáñez et al. (2017), entendiendo el TE como un macrogénero discursivo, indagaron en los géneros que lo conforman y a partir de los cuales se recontextualiza el conocimiento (Géneros del Conocimiento). Utilizando los criterios de: Propósito Comunicativo, Organización Discursiva y Modo Semiótico (Parodi, Venegas, Ibáñez \& Gutiérrez, 2008), analizaron un corpus constituido por 100 textos escolares del segundo ciclo de Educación Básica. Se identificaron 15 Géneros del Conocimiento (GCOs), en los que fue posible clasificar 11,139 instancias. También, constataron que, debido a los efectos de la variación disciplinar, la frecuencia de uso de los GCOs no fue la misma en todas las asignaturas (Matemáticas, Historia y Geografía, Ciencias Naturales, Lenguaje y Comunicación e Inglés), por lo que concluyen que las estrategias, tanto de enseñanza como de aprendizaje, deben adecuarse a las características de cada asignatura. Resultados como los anteriores contribuyen a nuestro entendimiento de cómo el conocimiento se recontextualiza en el TE. Sin embargo, esta no es la única forma. Según Martin y Rose (2013), la recontextualización también puede ser evidenciada a partir de la función que cumplen los GCOs. Adhiriendo a estos planteamientos, en este estudio se asume que en el TE, independiente de su propósito comunicativo, los GCOs pueden cumplir diversas funciones, las cuales varían dependiendo de la asignatura. Por ejemplo, la Noticia de Divulgación Científica corresponde a un GCO, cuyo propósito comunicativo es presentar eventos científicos recientes (Ibáñez et al., 2017). Sin embargo, en el TE de una asignatura ' $x$ ', este género podría ser utilizado para presentar los contenidos de una unidad, mientras que en una asignatura ' $y$ ', podría ser utilizado para contextualizar un problema. En este sentido, y con el propósito de continuar generando conocimiento en el área, parece razonable que antes de proceder a la descripción lingüístico estructural de los GCOs, se haga necesario conocer para qué son utilizados en el TE.

En este escenario, el presente estudio tuvo como objetivo caracterizar el proceso de recontextualización del conocimiento a partir de las funciones que cumplen los GCOs en el TE de Educación Básica de cinco asignaturas. Para ello, se analizaron las 11,139 instancias de los 15 GCOs reportados por Ibáñez et al. (2017) y se utilizaron las funciones generales propuestas por Martin y Rose (2013) como categorías clasificatorias de arranque. 
En la siguiente sección se presentan los conceptos teóricos que orientaron este estudio; a continuación, se describe el método empleado y, por último, se presentan y discuten los hallazgos más relevantes.

\section{Marco teórico}

\subsection{Recontextualización del conocimiento}

Considerando la naturaleza del proceso de recontextualización, una forma de comprenderlo en profundidad es integrando la perspectiva sociológica de Bernstein (1990) y la discursiva desarrollada desde la Lingüística Sistémico Funcional (Christie, 2002; Martin \& Rose, 2013).

Para explicar cómo se transfiere el conocimiento en contextos escolares, Bernstein (1990) plantea el concepto de dispositivo pedagógico, compuesto por estructuras sociales y sus reglas regulativas. Las estructuras sociales operan en tres niveles secuenciales: producción, recontextualización y reproducción. El primer nivel, denominado producción, concierne a todos aquellos estamentos donde se produce conocimiento especializado, como las universidades y centros de investigación. En este nivel, el conocimiento del estado de cosas del mundo se codifica en forma simbólica especializada. El segundo nivel corresponde a la recontextualización, donde la forma especializada es adaptada para ser comunicada en el contexto escolar. Según Bernstein (1990), en esta adaptación participan dos tipos de instituciones, las oficiales y las pedagógicas. Las instituciones oficiales corresponden a organismos públicos que controlan el quehacer pedagógico. En Chile, por ejemplo, el Ministerio de Educación se encarga de elaborar programas de estudios, delimitando los objetivos de aprendizaje que se alcanzarán en las aulas. Las instituciones pedagógicas corresponden a organismos que no controlan directamente la labor educativa, pero que, en cierta medida, pueden influir, como ocurre con las facultades de educación universitarias o los medios de comunicación especializados en educación. Una vez que el conocimiento ha sido adaptado en el nivel de la recontextualización, es utilizado en el tercer nivel, denominado reproducción. En este nivel se encuentran las prácticas pedagógicas, donde los conocimientos, por ejemplo, los contenidos en los programas de estudio se reconstruyen a partir del uso que le dan los estudiantes y los docentes en el aula.

Las reglas regulativas, por su parte, permiten la transferencia del conocimiento entre las diferentes estructuras sociales y se clasifican en tres tipos (Bernstein, 1990). El primer tipo corresponde a las reglas distributivas, las cuales controlan qué conocimiento se transmitirá y quiénes se encargarán de hacerlo. Ejemplo de estas reglas son las políticas públicas de distribución de recursos para educación. El segundo tipo corresponde a las reglas recontextualizadoras, las que seleccionan, refocalizan y vinculan distintos discursos, a partir de los cuales se enseña el conocimiento en el aula. 
Por ejemplo, las editoriales son agentes que ponen en funcionamiento estas reglas al elaborar los textos escolares. Por último, las reglas evaluativas regulan la transmisión y adquisición del conocimiento en la sala de clases. Un ejemplo de ello es la toma de decisiones de los docentes respecto a los discursos que utilizarán en las actividades de enseñanza-aprendizaje.

El mayor aporte del modelo de Bernstein (1990) para los estudios enmarcados en la lingüística educativa (Gee, 2001) es su planteamiento respecto de que la totalidad del funcionamiento del dispositivo pedagógico -interacción entre estructuras sociales y reglas regulativas- se realiza en el Discurso Pedagógico (DP). Según Bernstein (1990), a diferencia de otros tipos de discurso, como el discurso jurídico o el discurso político, el DP no posee un contenido propio, más bien, regula la forma en que se expresan otros tipos de discursos en contextos educativos. Por esta misma razón, el DP estaría compuesto por el Discurso Regulativo y el Discurso Instruccional. El primero controla y reproduce órdenes sociales, por ejemplo, la forma de secuenciar una clase a partir de la relación profesor-alumno. El segundo, transmite conocimiento desde diversas disciplinas, como ocurre en textos orales o escritos que explican contenidos de una asignatura (Bernstein, 1990).

Los planteamientos de Bernstein $(1981,1990)$ han sido reformulados desde la Lingüística Sistémico Funcional a partir de los constructos de registro y género discursivo (Christie, 1998, 2002; Martin \& Rose, 2008). Por una parte, se sostiene que el DP está constituido por el registro regulativo y el registro instruccional (Christie, 2002). El registro regulativo corresponde a las formas que se utilizan para secuenciar las actividades para el cumplimiento de objetivos didácticos, mientras que el registro instruccional corresponde a las formas utilizadas para la transmisión de contenidos disciplinares. Por otra parte, desde una mirada centrada en los géneros, se sostiene que el DP está constituido por dos tipos de géneros, los curriculares (GCUs) y los del conocimiento (GCOs). Los GCUs son entendidos por Christie (2002) como secuencias de actividades para lograr un determinado objetivo de aprendizaje (Planificaciones, Programas, etc.), mientras que los GCOs son aquellos que permiten transmitir conocimiento (Glosarios, Definiciones, etc.) (Martin \& Rose, 2013; Rose, 2014). Junto con lo anterior, también se sostiene que, en varias ocasiones, los GCUs conforman unidades mayores denominadas macrogéneros curriculares. Un ejemplo de ello es el TE, el que se configura a partir de diversos GCOs y GCUs (Martin \& Rose, 2013).

\subsection{La Recontextualización en el Texto Escolar}

Si bien en el TE la recontextualización se produce mediante el uso de GCUs y GCOs, son principalmente estos últimos los utilizados para la transmisión del conocimiento. Los GCOs no siempre corresponden a aquellos que circulan exclusivamente en ámbitos pedagógicos (Guía Didáctica, Definición, etc.), también se 
utilizan otros de circulación general (Noticia, Biografía, etc.). Del mismo modo, el uso de estos géneros varía dependiendo de la asignatura.

Un estudio que da cuenta de la variedad de géneros usados en el TE es la investigación de Ibáñez et al. (2017). Interesados por conocer la forma en que se transmite el conocimiento en este macrogénero, los autores caracterizaron los GCOs utilizados en el TE de cinco asignaturas (Lenguaje y Comunicación, Ciencias Naturales, Matemática, Historia y Geografía e Inglés) del segundo ciclo de Educación Básica chilena. Para ello, aplicaron tres criterios: propósito comunicativo, organización semiótica y modo de organización discursiva. Tras el análisis de 100 textos escolares, identificaron 15 GCOs, los que permitieron clasificar las 11,139 instancias encontradas en el corpus. De los 15 GCOs identificados en el estudio, 10 corresponden a géneros que circulan exclusivamente en el ámbito pedagógico (Espacio reflexivo, Recuento Histórico, etc.) y los 5 restantes a géneros de circulación general (Noticia de Divulgación Científica, Definición, Biografía y Fuente histórica).

Si bien los resultados de este estudio permiten observar cómo la recontextualización se realiza a partir de diferentes géneros discursivos, esta no es la única forma en que se puede evidenciar. De acuerdo con lo que sostienen Martin y Rose (2013), los GCOs presentan funciones primarias y secundarias. Desde esta perspectiva sistémico funcional, las funciones primarias se vinculan a un propósito social, lo que otros autores (al igual que en este trabajo) denominan el propósito comunicativo del género (Swales, 1990; Askehave \& Swales, 2001; Parodi et al., 2008). Por otra parte, las funciones secundarias están relacionadas con el uso contextualizado en la escuela, es decir, la función que el género cumple durante el proceso de recontextualización en contextos escolares. Por ejemplo, el género Mapa cumple la función primaria de representar gráficamente extensiones territoriales y en el TE podría ser utilizado para ejemplificar un contenido.

Martin y Rose (2013) proponen tres funciones secundarias generales, a partir de las cuales es posible agrupar una serie de GCOs: Comprometer al receptor, Informar y Evaluar determinados contenidos o puntos de vista. En la Figura 1 se presentan estas funciones generales y los géneros que las desempeñan. Cabe señalar que, con el propósito de clarificar la nomenclatura utilizada por los autores de la propuesta original, proporcionamos una versión traducida del inglés al español, la que, además, servirá como punto de arranque para la taxonomía que emerja a partir de nuestro análisis. 


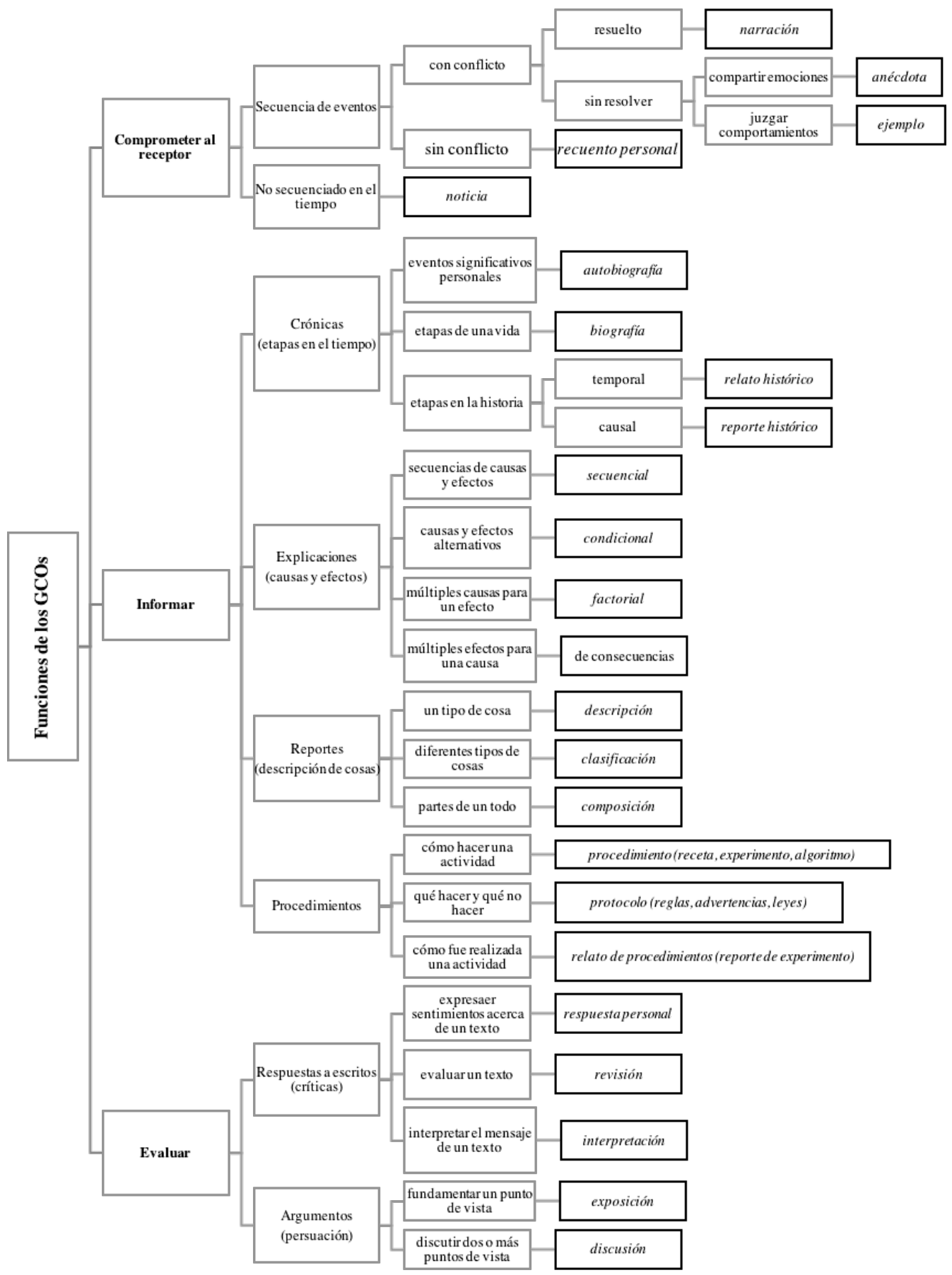

Figura 1. Géneros del Conocimiento en la escuela (Martin \& Rose, 2013: 235, traducción propia).

Como se observa en la Figura 1, la función Comprometer al receptor está orientada a que el estudiante adhiera a determinada información o se identifique con 
ciertos tópicos. Esta función es realizada en géneros como las anécdotas, ejemplos o narraciones. La función de Informar apunta a la exposición de contenidos de forma objetiva y se realiza en géneros de alto contenido disciplinar como explicaciones, reportes y procedimientos. Por último, la función de Evaluar apela a la subjetividad del estudiante ante contenidos disciplinares. Por lo tanto, esta función se realiza en géneros que posibilitan la persuasión o la crítica, como discusiones, debates e interpretaciones.

\section{Método}

De acuerdo con lo señalado en los apartados anteriores, el presente estudio tuvo como objetivo caracterizar el proceso de recontextualización del conocimiento a partir de las funciones que cumplen los GCOs en el TE de Educación Básica de cinco asignaturas.

\subsection{Corpus}

Se utilizó un corpus constituido por los 11,139 textos clasificados en los 15 GCOs identificados en el trabajo de Ibáñez et al. (2017). En la Tabla 1 se ofrece el detalle de ocurrencia y distribución por género y asignatura. Cabe señalar que el trabajo de Ibáñez et al. (2017) se llevó a cabo a partir de un corpus constituido por 100 textos escolares correspondientes a las asignaturas de Matemáticas, Historia y Geografía, Ciencias Naturales, Lenguaje y Comunicación e Inglés, utilizados en el segundo ciclo de Educación Básica $\left(5^{\circ}\right.$ a $8^{\circ}$ ), distribuidos por el Ministerio de Educación de Chile entre los años 2012 y 2016. 
Tabla 1. Distribución por género y asignatura.

\begin{tabular}{|c|c|c|c|c|c|c|}
\hline Géneros & Historia & $\begin{array}{c}\text { Lenguaje y } \\
\text { Comunicación }\end{array}$ & Matemática & $\begin{array}{l}\text { Ciencias } \\
\text { Naturales }\end{array}$ & Inglés & $\begin{array}{c}\text { TOTAL } \\
\text { POR } \\
\text { GÉNERO }\end{array}$ \\
\hline Biografía (BI) & 26 & 143 & 3 & 12 & 0 & 184 \\
\hline Nota (NOT) & 986 & 298 & 369 & 409 & 79 & 2141 \\
\hline $\begin{array}{l}\text { Espacio Reflexivo } \\
\text { (ER) }\end{array}$ & 4 & 0 & 0 & 80 & 0 & 84 \\
\hline Definición (DEF) & 335 & 589 & 118 & 107 & 83 & 1232 \\
\hline $\begin{array}{l}\text { Recuento } \\
\text { Histórico (RH) }\end{array}$ & 87 & 1 & 0 & 37 & 0 & 125 \\
\hline $\begin{array}{l}\text { Guía } \\
\text { Procedimental } \\
\text { (GP) }\end{array}$ & 181 & 147 & 628 & 63 & 36 & 1055 \\
\hline $\begin{array}{l}\text { Fuente Histórica } \\
(\mathrm{FH})\end{array}$ & 2628 & 0 & 0 & 0 & 0 & 2628 \\
\hline $\begin{array}{l}\text { Exposición de } \\
\text { Contenidos (EC) }\end{array}$ & 1199 & 447 & 222 & 666 & 14 & 2548 \\
\hline Mapa (MAP) & 439 & 0 & 0 & 0 & 0 & 439 \\
\hline $\begin{array}{l}\text { Síntesis } \\
\text { Conceptual (SC) }\end{array}$ & 51 & 1 & 7 & 55 & 2 & 116 \\
\hline $\begin{array}{l}\text { Dato Estratégico } \\
\text { (DE) }\end{array}$ & 0 & 1 & 0 & 0 & 131 & 132 \\
\hline $\begin{array}{l}\text { Comprobación } \\
\text { Empírica (CE) }\end{array}$ & 0 & 1 & 0 & 30 & 0 & 31 \\
\hline $\begin{array}{l}\text { Noticia de } \\
\text { Divulgación } \\
\text { Científica (NDC) }\end{array}$ & 0 & 0 & 0 & 123 & 0 & 123 \\
\hline $\begin{array}{l}\text { Expresiones } \\
\text { Frecuentes (EF) }\end{array}$ & 0 & 0 & 0 & 0 & 56 & 56 \\
\hline $\begin{array}{l}\text { Espacio } \\
\text { Metalingǘstico } \\
(\mathrm{EM})\end{array}$ & 0 & 0 & 0 & 0 & 245 & 245 \\
\hline $\begin{array}{l}\text { TOTAL POR } \\
\text { ASIGNATURA }\end{array}$ & 5936 & 1628 & 1347 & 1582 & 646 & 11139 \\
\hline
\end{tabular}

\subsection{Enfoque de análisis}

$\mathrm{Al}$ igual que en otros trabajos en los que se pretende identificar nuevas categorías y, en ese sentido, dar cuenta de la variación lingüística (Biber et al., 2007; Ibáñez et al., 2017), el análisis realizado en este trabajo adoptó un enfoque descendente-ascendente. El enfoque resultó en un marco de análisis de dos etapas complementarias, como se ilustra en la Tabla 2. 
Tabla 2. Marco de análisis para la identificación de categorías.

\begin{tabular}{|l|l|}
\hline ETAPAS & FASES METODOLÓGICAS \\
\hline DESCENDENTE & Revisión bibliográfica \\
& Selección de criterios \\
\hline \multirow{5}{*}{ ASCENDENTE } & Identificación de funciones en un microcorpus \\
& Levantamiento de funciones de los GCOs en el TE \\
& Etiquetaje \\
& Triangulación \\
& Agrupación de funciones identificadas \\
& Asociación de función identificada con una función general \\
& Ajuste de categorías \\
& Integración de nuevas categorías \\
& Aplicación de criterios al corpus de trabajo \\
& Validación con pares expertos \\
\hline
\end{tabular}

La etapa Descendente del marco está constituida por dos fases, las que involucran una indagación bibliográfica exhaustiva, a partir de la cual se selecciona una serie de criterios de análisis. En el presente estudio, primeramente se revisaron diferentes perspectivas respecto del concepto de Discurso Pedagógico y de las funciones que un género puede cumplir en contextos pedagógicos (Bernstein, 1981, 1990; Christie, 2002; Martin \& Rose, 2008). En lo que corresponde a la segunda fase de esta primera etapa, se seleccionó un modelo teórico que asume la existencia de tres funciones generales en las cuales los GCOs pueden ser agrupados, según la función que cumplen en contextos escolares (Martin \& Rose, 2013). La etapa Ascendente, por su parte, está conformada por cuatro fases y seis pasos metodológicos. En nuestro estudio, la primera fase involucró el levantamiento, etiquetaje y triangulación de funciones desde una muestra equivalente al 10\% del corpus. El levantamiento contempló observar, para cada caso, el uso pedagógico que se hacía del GCO en el contexto de una unidad de aprendizaje o lección. Los criterios utilizados para ello fueron los tipos de conocimiento, habilidades y actitudes que los estudiantes de Educación Básica deben desarrollar según lo declarado en las Bases Curriculares del Ministerio de Educación de Chile (MINEDUC, 2012). Esta labor fue desarrollada por ocho anotadores, estudiantes de pre y postgrado en el área del lenguaje y miembros del equipo de investigación. Los anotadores fueron entrenados durante tres meses en el proceso de análisis para que fueran capaces de distinguir el propósito comunicativo de un género de la función que este cumple en un TE particular. La segunda fase contempló agrupar las funciones identificadas, lo que en nuestro estudio se desarrolló, inicialmente, según las tres funciones secundarias generales ('Comprometer al receptor, Informar y Evaluar') propuestas por Martin y Rose (2013). Estas tres categorías iniciales fueron concebidas en este estudio como funciones generales y posterior a su modificación, durante los pasos de 'Ajuste de categorías e Integración de nuevas categorías', permitieron clasificar las funciones identificadas. En las últimas dos fases, se validaron las categorías y se analizó el corpus completo, procedimiento que se describe en detalle más adelante. 


\subsection{Procedimiento de análisis manual}

En el procedimiento de análisis manual, la tarea de los anotadores consistió en identificar la función de cada género en el TE. Los criterios utilizados fueron tres. El primero involucra la revisión de la unidad de aprendizaje propuesta en el TE a fin de reconocer sus objetivos de aprendizaje y el tema central. El segundo, implica determinar la relevancia de la información del texto respecto a los objetivos de aprendizaje de la unidad. El tercero involucra determinar el tipo de interacción entre los géneros de la unidad. A partir de la aplicación de estos tres criterios es posible reconocer una función específica de un género dentro del TE. A continuación, ilustramos el proceso de análisis mediante un ejemplo.

\section{CICLOS DE LA NATURALEZA}

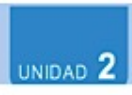

Interacciones en los ecosistemas

En los ecosistemas, los seres vivos interactúan entre ellos, esto se da porque comparten el mismo ambiente. Estas interacciones pueden ser para algunos organismos beneficiosas y perjudiciales para otros. Por ejemplo, si un águila se alimenta de un ratón, esta relación será favorable para el águila porque obtendrá alimento pero dañina para el ratón porque muere. Pero no todas las relaciones entre los seres vivos son de esta manera. Hay casos en que ambos organismos son beneficiados y otras en que son perjudicados; también es posible que uno sea beneficiado y el otro ni beneficiado ni perjudicado. Revisemos relaciones entre diferentes especies que comparten el ecosistema.

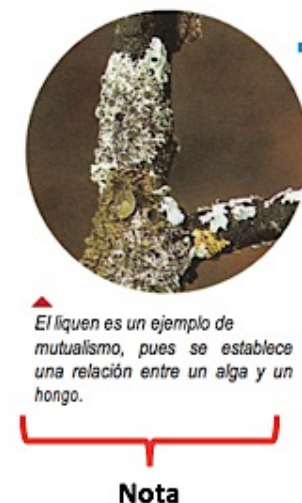

Mutualismo y protocooperación. Son dos tipos de interacciones que se caracterizan porque los dos organismos son beneficiados, la diferencia entre ellas es que la primera es obligatoria para ambos organismos, en cambio la segunda no lo es. Un ejemplo de mutualismo son las micorrizas, que es una asociación entre hongos y raices de plantas. Un ejemplo de protocooperación es la relación entre las flores y las abejas.

El liquen es un ejemplo de

Nota

Función: Complementar la información de una Exposición de Contenidos

Figura 2. Fragmento de texto escolar de Ciencias Naturales (7a Básico, 2012).

En la Figura 2 se presentan los géneros Exposición de Contenidos y Nota. Para determinar sus funciones, en primer lugar, se identificó el objetivo de aprendizaje de la unidad ('Describir los procesos básicos de los ciclos del agua, del carbono y del nitrógeno' y 'Conocer la importancia de los organismos productores y descomponedores, dentro de los diferentes ciclos biogeoquímicos') y se reconocieron los temas principales ('Ciclos de la materia' e 'Interacciones entre seres vivos'). En 
segundo lugar, se leyeron los textos y se identificó que la Exposición de Contenidos expone los temas centrales de la unidad (interacciones entre ecosistemas y sus tipos), mientras que Nota ejemplifica la temática de la Exposición de Contenidos. Por último, se identificó una relación de dependencia entre Nota y Exposición de Contenidos. Mientras que la Exposición de Contenidos presenta contenidos disciplinares centrales de una unidad o lección, la Nota complementa la información expuesta en la Exposición de Contenidos.

\subsection{Validación de las categorías definidas}

Con el objetivo de determinar si las funciones definidas se encuentran adecuadamente operacionalizadas, se realizó un proceso de validación de contenido a través del juicio de ocho pares expertos (Hatch \& Lazaraton, 1991; Escobar-Pérez \& Cuervo-Martínez, 2008). En todos los casos, los jueces eran estudiantes de postgrado y académicos de programas de postgrado en lingüística con experiencia en análisis de géneros discursivos. Para llevar a cabo el proceso de validación, se solicitó evaluar cada función en relación a su etiqueta, definición y ejemplo. Los expertos recibieron un correo electrónico en que se presentaba un cuestionario online con la información a evaluar. Cada juez evaluó la pertinencia de la función en el Texto Escolar. Las evaluaciones fueron analizadas a partir del coeficiente de acuerdo inter-juez o CAI (Cohen, 1966).

El proceso de evaluación de jueces expertos se realizó en una etapa, en que se validaron las 11 funciones, todas ellas con un mínimo de acuerdo de un 87\%. A nivel general, este procedimiento siguió la misma estructura de validación detallada por Ibáñez et al. (2017). Cabe destacar que todas las funciones fueron evaluadas a partir de un criterio de validación mínimo de un 80,4\% (Cohen, 1966).

\section{5. Índice de acuerdo entre anotadores}

Con el objetivo de evaluar el nivel de acuerdo presentado por los anotadores $(\mathrm{n}=$ 8), se usaron dos criterios de medición. El primero estuvo a la base de la confiabilidad o estabilidad de las respuestas de cada juez con relación a las anotaciones (etiquetas establecidas). Para evaluar la consistencia interna de cada evaluador, se calculó el coeficiente alfa de Cronbach. Los resultados muestran una consistencia interna que varía de aceptable a buena (alfa Cronbach mínima= 0.71; alfa de Cronbach máxima= 0.83), lo que permite concluir una adecuada consistencia de cada evaluador. En segunda instancia, se calculó un coeficiente de correlación a partir de la estimación de una Rho de Spearman, con el objetivo de establecer una medida de concordancia entre los jueces respecto a la asignación de cada etiqueta. A nivel general se obtuvieron correlaciones significativas y positivas en todos los casos, las que oscilaron de regular a moderada en todos los casos (rho mínimo= 0.51; rho máximo=0.66). En el Anexo 1 
se ilustra la distribución específica de los índices de confiabilidad interjueces para cada función.

\subsection{Plan de análisis estadístico}

Para dar cuenta de los objetivos de investigación, se realizó un análisis de distribución de frecuencias. En cada caso, se consideraron sus correspondientes porcentajes (Aron \& Aron, 2003). Con el objetivo de determinar si existían diferencias significativas en la proporción de ocurrencias de cada función, se realizó una prueba de Chi2.

\section{Resultados y discusión}

\subsection{Descripción general de las funciones en el Texto Escolar}

A continuación, se exponen las funciones identificadas en el corpus y su frecuencia. Como se aprecia en la Tabla 3, se identificaron 11 funciones desempeñadas por las 11,139 instancias de GCOs que constituyen el corpus.

Tabla 3. Distribución general de las funciones de los GCOs en el TE.

\begin{tabular}{|l|l|l|l|}
\hline \multicolumn{1}{|c|}{ Funciones } & \multicolumn{1}{|c|}{ f } & \multicolumn{1}{|c|}{$\%$} \\
\hline $1^{\circ}$ & Facilitar la comprensión de un contenido disciplinar & 3246 & 29,1 \\
\hline $2^{\circ}$ & Presentar contenidos disciplinares centrales de una unidad o lección & 3216 & 28,9 \\
\hline $3^{\circ}$ & Complementar la información de una Exposición de Contenidos & 2140 & 19,2 \\
\hline $4^{\circ}$ & Guiar el desarrollo de habilidades propias de una disciplina & 1054 & 9,5 \\
\hline $5^{\circ}$ & Facilitar la comprensión de textos curriculares & 821 & 7,4 \\
\hline $6^{\circ}$ & Guiar el desarrollo del conocimiento lingǘstico & 245 & 2,2 \\
\hline $7^{\circ}$ & Entregar un ejemplo contingente asociado al contenido de una unidad o lección & 123 & 1,1 \\
\hline $8^{\circ}$ & Consolidar los contenidos disciplinares & 115 & 1 \\
\hline $9^{\circ}$ & Desarrollar valores asociados a contenidos actitudinales & 84 & 0,8 \\
\hline $10^{\circ}$ & Facilitar el desarrollo de una habilidad comunicativa & 56 & 0,5 \\
\hline $11^{\circ}$ & $\begin{array}{l}\text { Promover la construcción autónoma de conocimientos disciplinares, centrales de } \\
\text { una unidad o lección }\end{array}$ & 30 & 0,3 \\
\hline & Total general & 11139 & 100 \\
\hline
\end{tabular}

En la Tabla 3, se observa que las funciones más frecuentes (en orden descendente) son: 'Facilitar la comprensión de un contenido disciplinar' $\left(f_{[11.139]}=3.246 ; 29,1 \%\right)$; 'Presentar contenidos disciplinares centrales de una unidad o lección' $\left(\mathrm{f}_{[11.139]}=3.216\right.$; $28,9 \%)$ y 'Complementar la información de una exposición de contenidos' $\left(\mathrm{f}_{[11.139]}=\right.$ $2.140 ; 19,2 \%)$. Todas ellas presentan proporciones significativamente superiores al resto de las funciones identificadas $\left(\mathrm{Chi}^{2}{ }_{[26.644]}=2,165 ; \mathrm{ps} \leq 0,001\right)$. No se observan diferencias significativas en las proporciones de representación de las funciones 'Facilitar la comprensión de un contenido disciplinar' y 'Presentar contenidos disciplinares centrales de una unidad o lección' $\left(\mathrm{Chi}^{2}{ }_{[26.644]}=0,981 ; \mathrm{ps}=0,326\right)$, siendo ambas la moda de representación. En contraste, las funciones con menor frecuencia de representación son: 'Promover la construcción autónoma de conocimientos disciplinares, centrales de una unidad o lección' $\left(\mathrm{f}_{[11.139]}=30 ; 0,3 \%\right)$; 'Facilitar el 
desarrollo de una habilidad comunicativa' $\left(\mathrm{f}_{[11.139]}=56 ; 0,5 \%\right)$ y 'Desarrollar valores asociados a contenidos actitudinales' $\left(\mathrm{f}_{[11.139]}=84 ; 0,8 \%\right)$. Todas ellas son significativamente inferiores al resto de las funciones $\left(\mathrm{Chi}^{2}{ }_{[26.644]}=2,931 ; \mathrm{ps} \leq 0,001\right)$, sin diferenciarse significativamente entre sí $\left(\mathrm{Chi}^{2}{ }_{[26.644]}=0,981\right.$; ps $\left.\geq 0,074\right)$.

Estos datos indican que no todas las funciones tienen la misma preponderancia en la recontextualización del conocimiento en el TE. De hecho, a pesar de la relevancia que tiene el desarrollo de actitudes en las Bases Curriculares (MINEDUC, 2012), la función 'Desarrollar valores asociados a contenidos actitudinales' presenta uno de los porcentajes de ocurrencia más bajos. Lo mismo sucede con la función 'Promover la construcción autónoma de conocimientos disciplinares, centrales de una unidad o lección', ya que, a partir de las indicaciones del currículum nacional, es de esperar que los estudiantes desarrollen un aprendizaje progresivamente autónomo (MINEDUC, 2012). Sin embargo, nuestros resultados sugieren que, en el TE chileno, aún no se favorece la autonomía progresiva del estudiante durante el proceso de aprendizaje (Moreno, 2003; Pozo \& Mateos, 2009).

Las funciones identificadas se agruparon inicialmente siguiendo las categorías propuestas por Martin y Rose (2013) para clasificar las funciones que cumplen los géneros en el discurso pedagógico (Comprometer al receptor, Informar y Evaluar contenidos o puntos de vista). En este estudio son entendidas como macrofunciones y utilizadas para clasificar las funciones secundarias que cumplen los géneros en el TE. Considerando la naturaleza descendente-ascendente de nuestro estudio y, dado que algunas de las funciones identificadas no son compatibles con las propuestas por Martin y Rose (2013), reformulamos la propuesta clasificatoria inicial, lo que permitió asegurar una descripción ad hoc al corpus. Más específicamente, se mantuvo la etiqueta Informativa, pero solo para agrupar las funciones asociadas a la exposición de conocimientos declarativos. La etiqueta Evaluar fue reemplazada por Valorativa, a fin de incluir las funciones asociadas al componente actitudinal. La etiqueta Comprometer al Receptor, por su parte, fue reemplazada por Complementaria, con el propósito de agrupar exclusivamente las funciones que facilitan el aprendizaje de conocimientos declarativos. Por último, a partir del análisis, emerge la categoría Orientadora, la que agrupa funciones asociadas al componente procedimental. De este modo, las 11 funciones identificadas fueron clasificadas en 4 macrofunciones, las que se presentan en la Tabla 4. 
Tabla 4. Macrofunciones y funciones en el TE.

\begin{tabular}{|l|l|l|}
\hline \multicolumn{1}{|c|}{$\begin{array}{c}\text { Macro- } \\
\text { funciones }\end{array}$} & \multicolumn{1}{|c|}{ Funciones de los GCOs en el texto escolar } & \multicolumn{1}{|c|}{$\begin{array}{c}\text { Frecuencia } \\
\text { (\%) }\end{array}$} \\
\hline Informativa & Presentar contenidos disciplinares centrales de una unidad o lección & 29,9 \\
\cline { 2 - 2 } & $\begin{array}{l}\text { Consolidar los contenidos disciplinares presentados en una unidad } \\
\text { o lección }\end{array}$ & \\
\hline Valorativa & Desarrollar valores asociados a contenidos actitudinales & 0,8 \\
\hline \multirow{5}{*}{$\begin{array}{l}\text { Complemen- } \\
\text { taria }\end{array}$} & Facilitar la comprensión de un contenido disciplinar & 56,8 \\
\cline { 2 - 2 } & Facilitar la comprensión de textos curriculares & \\
\cline { 2 - 2 } & $\begin{array}{l}\text { Entregar un ejemplo contingente asociado al contenido de una } \\
\text { unidad o lección }\end{array}$ & \multirow{2}{*}{12,5} \\
\cline { 2 - 2 } Orientadora & Complementar la información de una Exposición de Contenidos & \\
\cline { 2 - 2 } & Guiar el desarrollo de habilidades propias de una disciplina & \\
\cline { 2 - 2 } & Guiar el desarrollo del conocimiento lingüístico & $\begin{array}{l}\text { Promover la construcción autónoma de conocimientos disciplinares } \\
\text { centrales de una unidad o lección }\end{array}$ \\
\cline { 2 - 2 } & Facilitar el desarrollo de una habilidad comunicativa & \\
\hline
\end{tabular}

Tal como se aprecia en la Tabla 4, la macrofunción Complementaria es la más frecuente $\left(\mathrm{f}_{[11.139]}=6.330 ; 56,8 \%\right)$ y es significativamente superior al resto $\left(\mathrm{Chi}^{2}{ }_{[26.644]}=\right.$ $3,201 ; \mathrm{ps} \leq 0,001)$. Por otro lado, la macrofunción menos frecuente es la Valorativa $\left(\mathrm{f}_{[11.139]}=84 ; 0,8 \%\right)$, significativamente inferior a las demás $\left(\mathrm{Chi}^{2}{ }_{[26.644]}=3,411 ; \mathrm{ps} \leq\right.$ 0,001). Cabe destacar que no se observan diferencias significativas entre las macrofunciones Informativa y Orientadora $\left(\mathrm{Chi}^{2}{ }_{[26.644]}=1,003 ; \mathrm{p}=0,236\right)$. Esta mirada general revela la preponderancia de las funciones que pertenecen a la macrofunción Complementaria, lo que permite observar que el conocimiento no se recontextualiza exclusivamente a partir de la exposición de contenidos. Por el contrario, se hace principalmente por medio de funciones complementarias que andamian la exposición $y$, en este sentido, propician mayores oportunidades de aprendizaje (Mullis, Martin, Smith, Garden, Gregory, González, Chrostowski \& O’Connor, 2003).

Los datos hasta aquí expuestos revelan la variedad y frecuencia de funciones identificadas en el corpus, lo que ofrece una panorámica general respecto a cómo la recontextualización se materializa en el TE. A continuación, y desde una mirada más pormenorizada, se presentan, en primer lugar, los GCOs asociados a las funciones y, posteriormente, la distribución de estas entre las asignaturas.

\subsection{Distribución de las funciones según los GCOs}

A continuación, se presentan los GCOs y las respectivas funciones que desempeñan en el TE (ver Anexo 2 para revisar ejemplos extraídos del corpus). 


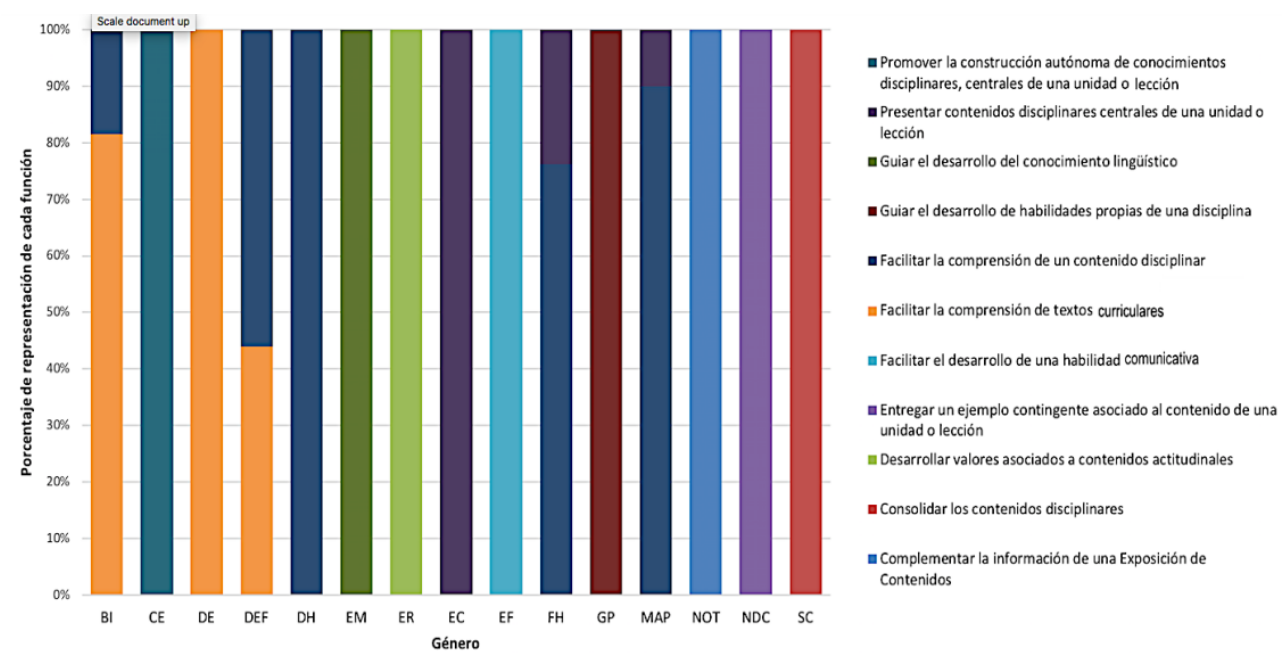

Figura 3. Funciones que cumple cada GCO.

Como se observa en la Figura 3, de los 15 GCOs considerados en el estudio, 11 desempeñan solo una función. Por ejemplo, el género Comprobación Empírica cumple exclusivamente la función 'Promover la construcción autónoma de conocimiento disciplinar'. También se observa que 4 GCOS desempeñan dos funciones. La Definición, por ejemplo, cumple las funciones 'Facilitar la comprensión de un contenido disciplinar' y 'Facilitar la comprensión de textos curriculares'.

Cabe señalar además que, en todos los GCOs que cumplen dos funciones (Biografía, Definición, Fuente Histórica y Mapa), predomina significativamente una $\left(\mathrm{Chi}^{2}{ }_{[166]} \geq 1,441\right.$; ps $\left.\leq 0,018\right)$, la que entenderemos como principal, opuesta a una subsidiaria. Entre estos GCOs, el género Definición presenta la menor diferencia entre su función principal $(56 \%)$ y su función subsidiaria (44\%), mientras que el género Mapa presenta la mayor diferencia ( $90 \%$ y 10\%, respectivamente). A partir de estos datos, se puede inferir que en el proceso de recontextualización los géneros tienden hacia una especialización en la función que desempeñan.

También se observa que en el TE se utilizan géneros que usualmente circulan en contextos distintos al pedagógico (Mapa, Definición, Biografía, entre otros). Dado el efecto de las reglas recontextualizadoras del dispositivo pedagógico (Bernstein, 1990), en este nuevo contexto, dichos géneros desempeñan funciones diferentes a su propósito comunicativo. Esto es coherente con los planteamientos de Martin y Rose (2013), quienes sostienen que existen géneros que poseen una función primaria, pero que en el contexto pedagógico pueden llegar a cumplir otras funciones. En el caso del Mapa, por ejemplo, nuestros datos indican que si bien su propósito comunicativo es representar gráficamente extensiones territoriales (Ibáñez et al., 2017), en el TE se utiliza principalmente para 'Facilitar la comprensión de un contenido disciplinar' y en 
menor medida para 'Presentar contenidos disciplinares centrales de una unidad o lección'.

Los datos hasta aquí expuestos permiten identificar las funciones desempeñadas por los GCOs. Desde una mirada inversa, focalizada en los GCOs utilizados para cumplir las funciones, se observa que 8 de estas son desempeñadas por un solo GCO, mientras que 3, por más de uno. La Figura 4 presenta el detalle de las funciones y los GCOs que las desempeñan.

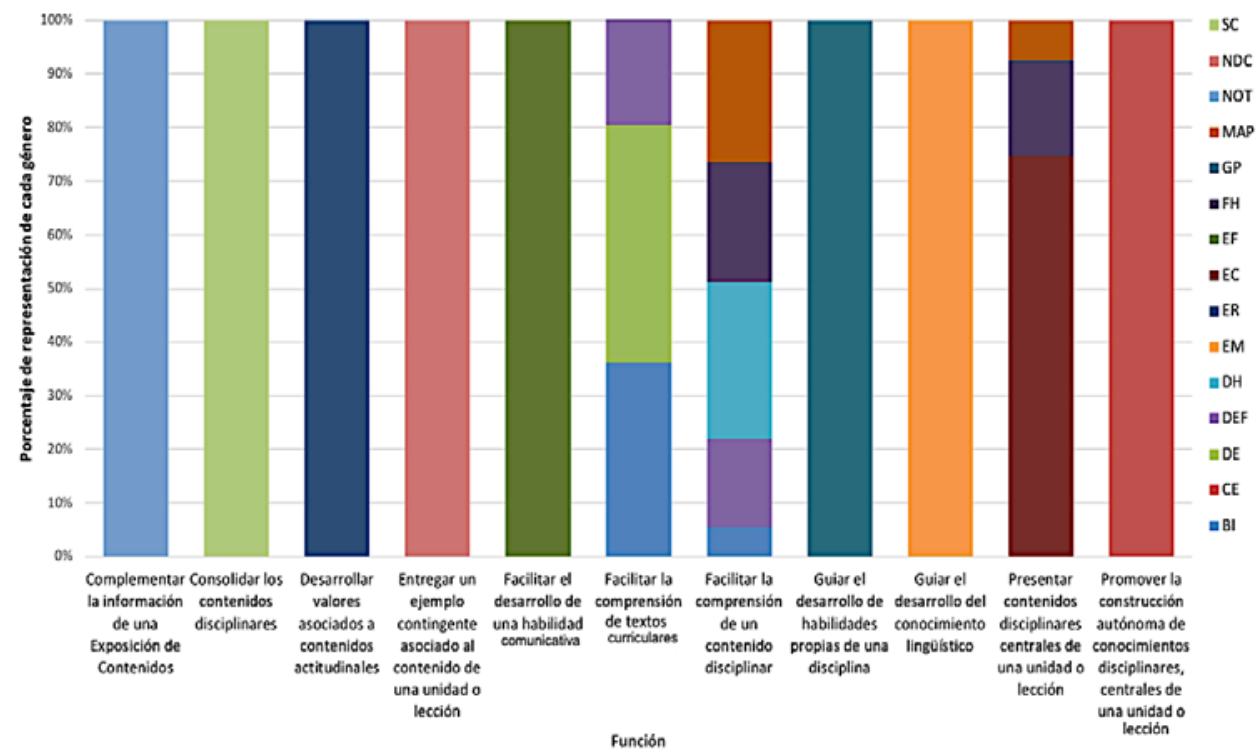

Figura 4. GCOs en los que se realiza cada función.

En la Figura 4 se observa que la función 'Facilitar la comprensión de un contenido disciplinar' se realiza por medio de cinco GCOs, mientras que las funciones 'Facilitar la comprensión de un texto curricular' y 'Presentar contenidos disciplinares centrales de una unidad o lección' se realizan por medio de tres GCOs. Junto con lo anterior, es relevante destacar que la función desempeñada por una mayor cantidad de géneros, pertenece a la macrofunción Complementaria. Esto reafirma la preocupación por el uso de una variedad de recursos que favorezcan mayores oportunidades de aprendizaje.

\subsection{Distribución de las funciones entre asignaturas}

Desde esta nueva mirada, nuestros datos revelan diferencias disciplinares importantes. En la Figura 5 se detalla la ocurrencia de cada función entre las asignaturas. 


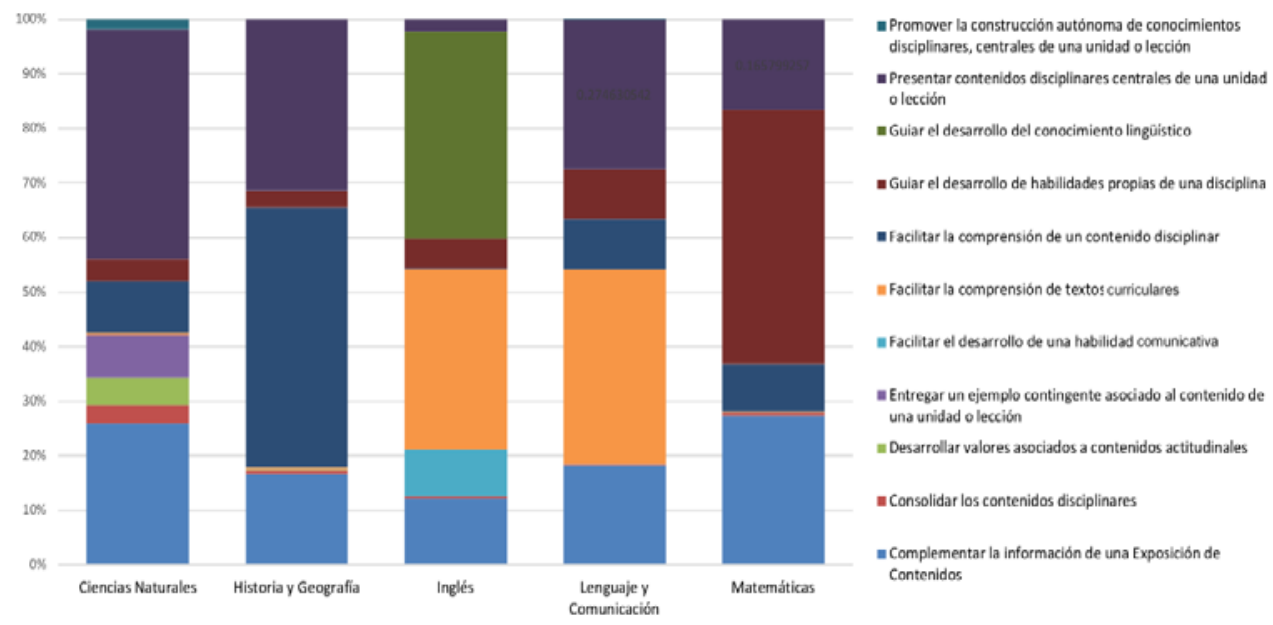

Figura 5. Funciones en cada Asignatura.

En la Figura 5, se observa que si bien existen funciones que son transversales a las asignaturas, su frecuencia varía entre estas. Por ejemplo, la función 'Presentar contenidos disciplinares de una unidad o lección' tiene una frecuencia importante en Ciencias Naturales (42\%), pero es considerablemente menor en Matemática (16\%) y completamente marginal en Inglés $(2 \%)$. Junto con lo anterior, se aprecia que en 4 asignaturas (Ciencias Naturales, Historia y Geografía, Lenguaje y Comunicación, y Matemática) predomina una función diferente, siendo en todos los casos estadísticamente significativos $\left(\mathrm{Chi}^{2}{ }_{[2.648]}=3,004 ; \mathrm{p} \leq 0,001\right)$. Asimismo, se observa que en una asignatura (Inglés), predominan dos funciones, sin diferencias significativas entre sí $\left(\mathrm{Chi}^{2}{ }_{[1.138]}=0,331 ; \mathrm{p}=0,211\right)$. Más específicamente, en Ciencias Naturales la función predominante es 'Presentar contenidos disciplinares centrales de una unidad o lección' (42\%), mientras que en Historia y Geografía, lo es 'Facilitar la comprensión de un contenido disciplinar' (48\%); en Lenguaje y Comunicación y Matemática predomina la función 'Facilitar la comprensión de textos curriculares' (36\%) y 'Guiar el desarrollo de habilidades propias de una disciplina' (47\%) respectivamente. Por último, en el caso de Inglés, predominan las funciones de 'Guiar el desarrollo del conocimiento lingüístico' (38\%) y 'Facilitar la comprensión de un texto curricular' $(33 \%)$.

Considerando que cada disciplina comunica su conocimiento según sus propias convenciones discursivas (Bhatia, 2004; Hyland, 2004; Samraj, 2008), resulta lógico que estas diferencias sean también parte del proceso de recontextualización (Bernstein, 1996). Esto implica que el conocimiento disciplinar sea adaptado según la naturaleza de cada asignatura del curriculum (Wheelahan, 2010), razón por la cual estas priorizarían una función por sobre otra. Por ejemplo, en Matemática la predominancia de la función 'Guiar el desarrollo de habilidades propias de una disciplina' es 
congruente con el propósito de la asignatura, que es incrementar el uso de las habilidades: resolver problemas, representar, modelar y argumentar, y comunicar (MINEDUC, 2012). Asimismo, en Ciencias Naturales predomina la función 'Presentar contenidos disciplinares centrales de una unidad o lección', lo que va en línea con los planteamientos del MINEDUC (2012), respecto de la necesidad de que los estudiantes aprendan conocimientos científicos relevantes.

La predominancia de funciones en las asignaturas no solo se evidencia al considerar las 11 funciones identificadas, sino que también a partir de las macrofunciones propuestas, tal como se observa en la Tabla 5.

Tabla 5. Distribución de proporciones de las macrofunciones según asignatura (en \%).

\begin{tabular}{|l|c|l|l|l|l|}
\hline & $\begin{array}{c}\text { Ciencias } \\
\text { Naturales }\end{array}$ & $\begin{array}{c}\text { Historia y } \\
\text { Geografía }\end{array}$ & Inglés & $\begin{array}{c}\text { Lenguaje y } \\
\text { Comunicación }\end{array}$ & Matemáticas \\
\hline Informativa & 45,6 & 32,3 & 2,5 & 27,5 & 17,1 \\
\hline Valorativa & 5,1 & 0,1 & 0,0 & 0,0 & 0,0 \\
\hline Complementaria & 43,5 & 64,6 & 45,4 & 63,4 & 36,3 \\
\hline Orientadora & 5,8 & 3,0 & 52,2 & 9,1 & 46,6 \\
\hline Total & 100 & 100 & 100 & 100 & 100 \\
\hline
\end{tabular}

Desde una mirada global, cuando se contrastan las macrofunciones en cada asignatura, el panorama varía levemente. Así, y tal como se observa en la Tabla 5, la función Complementaria es significativamente predominante en Lenguaje y Comunicación $\left(\mathrm{Chi}^{2}{ }_{[1.138]}=2,443 ; \mathrm{p}=0,002\right)$. Esto se explica en la alta presencia de la función 'Facilitar la comprensión de textos curriculares', lo que es congruente con la preponderancia que tiene en la asignatura el desarrollo de la comprensión de textos escritos (MINEDUC, 2012). En el resto de las asignaturas predominan dos macrofunciones, sin diferencias significativas entre ellas $\left(\mathrm{Chi}^{2}{ }_{[1.138]}=1,013\right.$; ps $\left.>0,061\right)$. Por ejemplo, se observa que tanto en Ciencias Naturales como en Historia y Geografía predominan las macrofunciones Informativa y Complementaria, mientras que en Inglés y Matemática predominan las macrofunciones Complementaria y Orientadora. La predominancia de estas macrofunciones en estas dos últimas asignaturas es coherente con uno de los focos centrales de estas asignaturas: la enseñanza de contenidos procedimentales, por sobre los declarativos.

\section{CONCLUSIONES}

Entre los resultados generales se destaca el hallazgo de 11 funciones de los GCOs en el TE, las cuales, dada su naturaleza, fueron agrupadas en cuatro macrofunciones emergentes: Informativa, Valorativa, Complementaria y Orientadora. Las funciones más frecuentes son 'Facilitar la comprensión de un contenido disciplinar' y 'Presentar contenidos disciplinares centrales de una unidad o lección', alcanzando entre ambas un 58\% de presencia en el corpus. Estas dos funciones corresponden a macrofunciones distintas, la primera se identifica como Complementaria y la segunda 
como Informativa. Este equilibrio entre las dos macrofunciones permite inferir que el macropropósito del TE -instruir acerca de los conocimientos declarativos y procedurales propios de una disciplina- no se remite solo a la exposición de contenidos disciplinares, sino al andamiaje de estos a través de otros recursos de aprendizaje.

Otro hallazgo relevante es la cantidad de funciones desempeñadas por cada GCO. Se observa que solo cuatro de los quince GCOs desempeñan dos funciones y los once restantes, solo desempeñan una. Junto con lo anterior, se observa que, en aquellos casos en que un GCO cumple dos funciones, una de ellas tiene predominancia significativa por sobre la otra. Esto nos permite proponer que en los textos escolares analizados, la variación de funciones con la que los GCOS son utilizados es mínima. Es decir, existe un alto grado de especificidad entre GCO y su función en el TE.

Respecto a las funciones predominantes en cada asignatura, se presentan claras diferencias pues, de las 5 asignaturas revisadas, ninguna comparte una función predominante. Esto evidencia la influencia de la variación disciplinar en el proceso de recontextualización del conocimiento. Así como las disciplinas presentan diversas formas de comunicar el conocimiento (Bhatia, 2004; Hyland, 2004), a nivel escolar ocurre el mismo fenómeno. A modo de ejemplo, Inglés que presenta exclusivamente las funciones 'Facilitar el desarrollo de una habilidad comunicativa' y 'Guiar el desarrollo del conocimiento lingüístico'. Esta asignatura demuestra la recontextualización de los conocimientos disciplinares respecto al aprendizaje de L2, enfocándose en el desarrollo de habilidades y estrategias comunicativas por sobre el aprendizaje memorístico de contenidos gramaticales (MINEDUC, 2012).

Junto con la especificidad observada en las funciones que cumplen los GCOs y la variación en la frecuencia de las funciones entre asignaturas, también se advierte que gran parte de las funciones son transversales a las asignaturas. Se concluye, por lo tanto, que el TE, y el DP en general, cuenta con características relativamente estables. Esto corrobora los planteamientos de Bernstein (1996) respecto a cómo el conocimiento disciplinar no puede comunicarse en el contexto pedagógico exclusivamente desde la lógica de la disciplina. Por ello, en la recontextualización se selecciona y refocaliza el conocimiento con formas prototípicas, como se ha observado en esta investigación, en la transversalidad de determinadas funciones.

Puesto que el conocimiento disciplinar se recontextualiza en las asignaturas de acuerdo con las características de cada disciplina, la forma de acceder a este conocimiento en el aula estará determinada por la función de los GCOs. Por esta razón, identificar las funciones de los GCOs en el TE y observar su variación en las asignaturas conlleva implicancias pedagógicas relevantes. Por lo mismo, los datos empíricos que ofrecemos pueden ser de utilidad no solo para el profesor de aula que necesita elaborar herramientas didácticas para sus clases, sino que también podrían ser 
relevantes como material de consulta para las editoriales dedicadas a la elaboración de textos escolares. Incluso, quizás quienes podrían beneficiarse aún más con los datos aquí reportados son las casas de estudio a cargo de la formación de profesores. En este último punto, cabe señalar que, dada la relevancia de la multisemiosis en la recontextualización del conocimiento, un futuro trabajo debiera contemplar la caracterización multisemíotica de los GCOs. Esto sin duda fortalecería el aporte de este tipo de trabajos en ámbitos escolares y editoriales.

\section{REFERENCIAS BIBLIOGRÁFICAS}

Achugar, M. \& Schleppegrell, M. (2005). Beyond connectors: The construction of cause in history textbooks. Linguistics and Education, 16, 298-318.

Aron, A. \& Aron, E. N. (2003). Statistics for psychology. Nueva Jersey: Pearson Education Inc.

Askehave, I. \& Swales, J. (2001). Genre identification and communicative purpose: A problem and a possible solution. Applied Linguistics, 22(2), 195-212.

Ávila, D., Barletta, N. \& Chamorro, D. (2017). La representación de la revolución en el texto escolar: 'Ser' y 'llegar a ser' en la historia. Revista Signos. Estudios de Lingüística, 50(94), 150-173.

Barletta, N. \& Chamorro, D. (2011). Las unidades textuales: Organizadoras del texto. En D. Chamorro \& N. Barletta (Eds.), El texto escolar y el aprendizaje. Enredos y desenredos (pp. 16-26). Barranquilla: Editorial Universidad del Norte.

Bernstein, B. (1981). Codes, modalities, and the process of cultural reproduction: A model. Language in Society, 10(3), 327-363.

Bernstein, B. (1990). The structuring of pedagogic discourse: Class, codes \& control, Volume IV. Londres: Routledge.

Bernstein, B. (1996). Pedagogy, symbolic control and identity. Londres: Taylor and Francis.

Bhatia, V. (2004). Worlds of written discourse: A genre based view. Londres: Continuum.

Biber, D., Connor, U. \& Upton, T. (2007). Discourse on the move: Using corpus analysis to describe discourse structure. Ámsterdam: John Benjamins.

Chamorro, D., Mizuno, J. \& Moss, G. (2011). Tergiversaciones y correspondencias: La metáfora y sus bemoles. En D. Chamorro \& N. Barletta (Eds.), El texto escolar y el aprendizaje. Enredos y desenredos (pp. 101-122). Barranquilla: Editorial Universidad del Norte.

Choppin, A. (1998). Los manuales escolares. Historia y actualidad. París: Hachette. 
Christie, F. (1998). Pedagogy and the Shaping of Consciousness: Linguistic and social processes. Londres: Cassell (Open Linguistics Series).

Christie, F. (2002). Classroom discourse analysis: A functional perspective. Londres: Continuum.

Cohen, J. D. (1966). The Impact of Multivariate Research in Clinical Psychology. En R. B. Cattell (Ed.), Handbook of Multivariate Experimental Psychology (pp. 174243). Chicago: Rand McNally.

Díaz-Levicoy, D. \& Cezón, P. (2017). Análisis de gráficos estadísticos en textos escolares de séptimo básico en Chile. Revista Electrónica Diálogos Educativos, 14(28), 21-40.

Escobar-Pérez, J. \& Cuervo-Martínez, A. (2008). Validez de contenido y juicio de expertos: Una aproximación a su utilización. Avances en medición, 6(1), 27-36.

Espinoza, J. (2012). El texto escolar como artefacto cultural: Estudio sobre representación de la Identidad Nacional en textos escolares de Historia durante la dictadura civil-militar en Chile (1973-1990). Paulo Freire. Revista de Pedagogía Crítica, 11(11), 69-83.

Fernández, M. (2010). Las mujeres en el discurso pedagógico de la historia: Exclusiones, silencios y olvidos. Universum (Talca), 25(1), 84-99.

Gee, J. (2001). Educational linguistics. En M. Aronoff \& J. Rees-Miller (Eds.), The bandbook of linguistics (pp. 647-663). Oxford: Blackwell.

Hatch, E. \& Lazarton, A. (1991). The research manual. Design and statistics for applied linguistics. Massachusetts: Heinle \& Heinle Publishers.

Hyland, K. (2004). Disciplinary Discourses: Social Interactions in Academic Writing. Ann Arbor: University of Michigan Press.

Ibáñez, R., Moncada, F., Cornejo, F. \& Arriaza, V. (2017). Los Géneros del Conocimiento en Textos Escolares de educación primaria. Calidoscópio, 15(3), 462-476.

Leyton, G., Ávalos, C. \& Calderón, C. (2018). Enseñanza de Temas Conflictivos de la Historia del Tiempo Presente en Libros de Textos de Chile y Argentina. Cadernos de pesquisa: Pensamento Educacional, 13(33), 234-253.

Martin, J. \& Rose, D. (2008). Genre relations: Mapping culture. Sydney: Equinox.

Martin, J. \& Rose, D. (2013). Pedagogic Discourse: Contexts of Schooling. RASK: International Journal of Language and Communication, 38, 219-264. 
Meneses, A., Montenegro, M. \& Ruiz, M. (2014). Textos escolares para aprender ciencias: Habilidades, contenidos y lenguaje académico. En M. de la Cerda (Ed.), Evidencias para políticas públicas en educación: Selección de investigaciones, Sexto Concurso FONIDE (pp. 233-277). Santiago de Chile, Ministerio de Educación de Chile-División de Planificación y Presupuesto-Centro de Estudios MINEDUC.

MINEDUC. (2012). Bases Curriculares para la Enseñanza Básica. Santiago: MINEDUC.

Moreno, M. (2003). Estrategias de aprendizaje: Bases para la intervención psicopedagógica. Revista Psicopedagogía, 20(62), 136-142.

Moss, G. (2009). Los textos escolares en Ciencias Sociales y Ciencias Naturales y su relación con los procesos de aprendizaje. El caso de Colombia. Delta: Documentos de estudios en lingǘstica teórica y aplicada, 25, 657-683.

Mullis, I., Martin, M., Smith, T., Garden, R., Gregory, K., Gonzalez, E., Chrostowski, S. \& O'Connor, K. (2003). TIMSS assessment frameworks and specifications 2003. Chestnut Hill, MA: Boston College.

Olivares, P. (2007). Concepto de nación e identidad nacional: Una approache a través de las políticas educativas y de la enseñanza de la Historia de Chile (siglos XIX-XX). En MINEDUC (Ed.), Acta del Primer Seminario Internacional de Textos Escolares (pp. 161-165). Santiago de Chile: Mineduc-Unesco.

Oteíza, T. (2009a). Solidaridad ideológica en el discurso de la historia: Tensión entre orientaciones monoglósicas y heteroglósicas. Revista Signos. Estudios de Lingüistica, 42(70), 219-244.

Oteíza, T. (2009b). Cómo es presentada la historia contemporánea en los libros de textos chilenos para la escuela media. Discurso \& Sociedad, 3(1), 150-174.

Oteíza, T. (2014). Intertextualidad en la recontextualización pedagógica del pasado reciente chileno. Discurso \& Sociedad, 8(1), 109-136.

Oteíza, T. \& Pinuer, C. (2016). Des/legitimación de las memorias históricas: Valoración en discursos pedagógicos intermodales de enseñanza básica chilena. Revista Signos. Estudios de Lingüistica, 49(92), 377-402.

Parodi, G., Venegas, R., Ibáñez, R. \& Gutiérrez, R. (2008). Los géneros del discurso en el Corpus PUCV-2006: Criterios, definiciones y ejemplos. En G. Parodi (Ed.), Géneros académicos y géneros profesionales: Accesos discursivos para saber y hacer (pp. 43-59). Valparaíso: EUV.

Pereira, F. \& González, G. (2011). Análisis descriptivo de Textos Escolares de Lenguaje y Comunicación. Literatura y lingüística, 24, 161-182. 
Pinuer, C. \& Oteíza, T. (2016). La construcción léxico-gramatical de significación histórica en manuales escolares chilenos. Revista de lingüística teórica y aplicada, 54(1), 51-77.

Pozo, J. \& Mateos, M. (2009). Aprender a aprender: Hacia una gestión autónoma y metacognitiva del aprendizaje. En J. I. Pozo \& M. P. Pérez Echeverría (Coords.), Psicología del aprendizaje universitario: La formación en competencias (pp. 54-69). Madrid: Ediciones Morata.

Riedemann, A. (2010). Textos escolares y conciencia histórica publicada sobre la ocupación de la Araucanía. Ponencia presentada en el Seminario Textos Escolares y Enseñanza de la Historia en Chile, Mineduc, Santiago, Chile.

Rose, D. (2014). Analyzing pedagogic discourse: An approach from genre and register. Functional Linguistics, 1, 11.

Ruiz, M., Meneses, A. \& Montenegro, M. (2014). Coherencia curricular y oportunidades para aprender Ciencias. Ciência \& Educação (Bauru), 20(4), 955970 .

Ruiz, M., Montenegro, M., Meneses, A. \& Venegas, A. (2016). Oportunidades para aprender ciencias en el currículo chileno: Contenidos y habilidades en educación primaria. Perfiles educativos, 38(153), 16-33.

Samraj, B. (2008). A discourse analysis of master's theses across disciplines with a focus on introductions. Journal of English for Specific Purposes, 7, 55-67.

Swales, J. (1990). Genre analysis. English in academic and research settings. Cambridge: Cambridge University Press.

Tamayo, M. (2007). Análisis de textos escolares chilenos relativos a la evolución biológica. En MINEDUC (Ed.), Acta del Primer Seminario Internacional de Textos Escolares (pp. 156-160). Santiago de Chile: Mineduc-Unesco.

Wheelahan, L. (2010). Why knowledge matters in curriculum. Londores: Rouledge Taylor and Francis Group.

Zúñiga, E. (2007). Los indios en los relatos históricos del pasado de la nación.160 años de textos escolares de Historia de Chile (1845-2005). En MINEDUC (Ed.), Acta del Primer Seminario Internacional de Textos Escolares (pp. 176-182). Santiago de Chile: Mineduc-Unesco. 


\section{ANEXO 1}

\section{Índices de confiabilidad inter-juez $(n=8)$ por función}

\begin{tabular}{|l|c|c|}
\hline & $\begin{array}{c}\text { Coeficiente } \boldsymbol{\alpha} \text { de } \\
\text { Cronbach }\end{array}$ & $\begin{array}{c}\text { Coeficiente Rho de } \\
\text { Spearman }\end{array}$ \\
\hline $\begin{array}{l}\text { Complementar la información de una exposición de } \\
\text { contenidos }\end{array}$ & 0.74 & $0.57^{* *}$ \\
\hline Consolidar los contenidos disciplinares & 0.77 & $0.59^{* *}$ \\
\hline Desarrollar valores asociados a contenidos actitudinales & 0.71 & $0.51^{* *}$ \\
\hline $\begin{array}{l}\text { Entregar un ejemplo contingente asociado al contenido } \\
\text { de una unidad o lección }\end{array}$ & 0.84 & $0.63^{* *}$ \\
\hline Facilitar el desarrollo de una habilidad & 0.85 & $0.65^{* *}$ \\
\hline Facilitar la comprensión de textos curricular & 0.86 & $0.66^{* *}$ \\
\hline Facilitar la comprensión de un contenido disciplinar & 0.85 & $0.65^{* *}$ \\
\hline $\begin{array}{l}\text { Guiar el desarrollo de habilidades propias de una } \\
\text { disciplina }\end{array}$ & 0.80 & $0.61^{* *}$ \\
\hline Guiar el desarrollo del conocimiento lingüístico & 0.81 & $0.62^{* *}$ \\
\hline $\begin{array}{l}\text { Presentar contenidos disciplinares centrales de una } \\
\text { unidad o lección }\end{array}$ & 0.84 & $0.62^{* *}$ \\
\hline $\begin{array}{l}\text { Promover la construcción autónoma de conocimientos } \\
\text { disciplinares, centrales de una unidad o lección }\end{array}$ & 0.71 & $0.52^{* *}$ \\
\hline
\end{tabular}

$* * \mathrm{p} \leq 0,01$ 


\section{ANEXO 2 \\ Ejemplo de GCOs y su función en textos escolares}

\section{Ejemplo 1}

\section{Extraído del texto de 70 básico de Ciencias Naturales, año 2012}

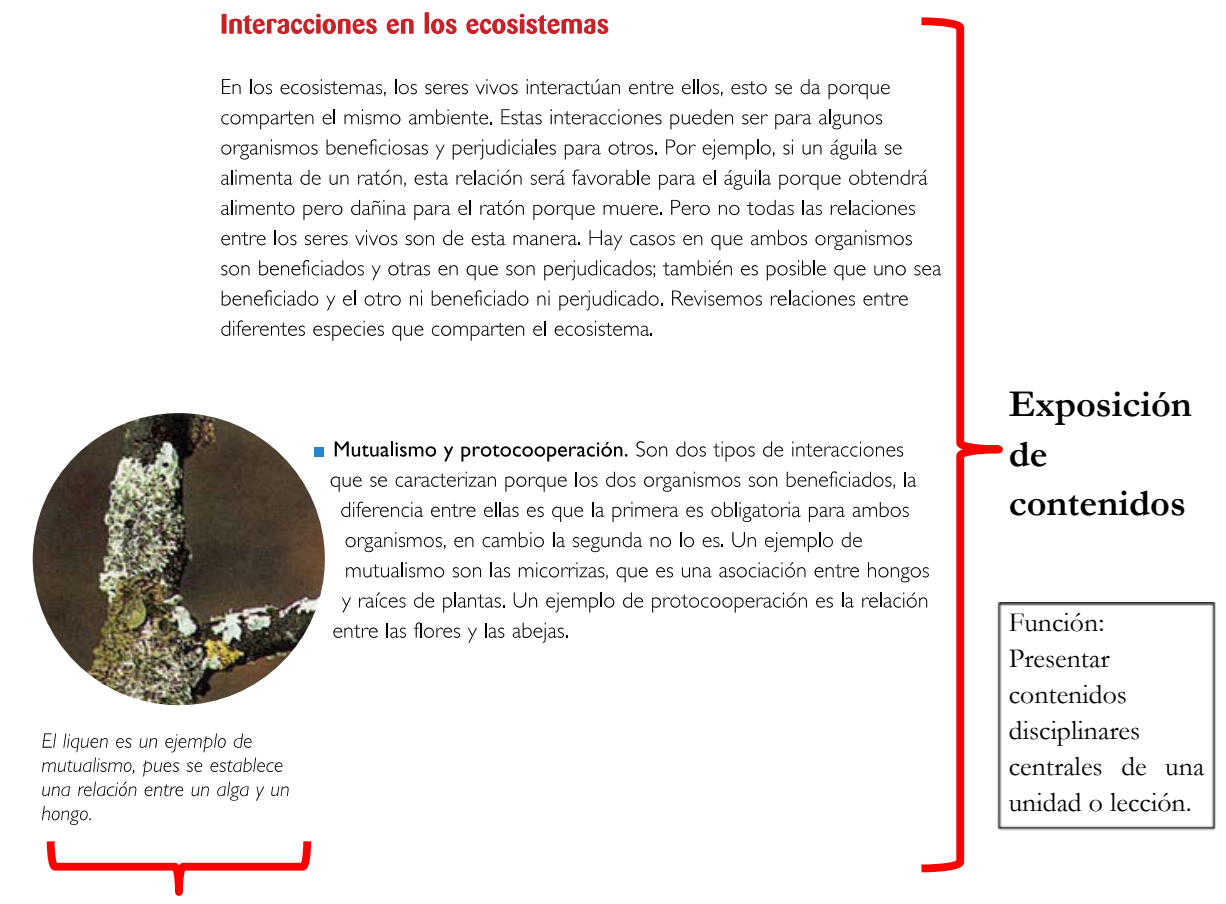

Nota

Función: Complementar la

información de una Exposición

de Contenidos 


\title{
Ejemplo 2
}

\section{Extraído del texto de 70 básico de Historia y Geografía, año 2015}

\begin{abstract}
Las polis griegas se unieron en la guerra en defensa de su libertad

Cada ciudad-estado griega resguardaba celosamente su independencia. sin embargo, hubo episodios cruciales en que las polis se unieron en defensa de su libertad y valores compartidos. Uno de estos fue el enfrentamiento con los ejércitos y flotas del poderoso Imperio Persa: en el periodo 490 a 479 a.C. los griegos libraron las dos Guerras Médicas (estas recibieron su nombre del pueblo medo, aliado de los persas y parte del imperio).

En el año 493 a.C. los ejércitos del emperador Darío partieron desde la ciudad de Sardes, capital de la provincia más occidental del Impenio Medo-Persa, con el objetivo de someter a los griegos. En septiembre del año 490 a.C. el ejército ateniense derrotó a los persas en Maratón. Diez años después, el hijo de Darío, Jerjes, salió de Sardes con un ejército de más de oen mil hombres y, ante esta nueva amenaza, las polis gricgas se unieron en una liga militar dirigida por Esparta. Tras derrotar a 300 espartanos y otros cinco mil 600 griegos en el paso de las Termópilas. los persas invadieron y devastaron Beocia y el Ática. El lider ateniense Temistocles hizo evacuar su ciudad y, vencida la resistencia en la acrópolis. Jerjes saqueó y quemb Átenas. En una acción decisiva, la amada griega venció a la flota persa en la batalla de Salamina luego el ejército derrotó a los persas en Platea y, finalmente, su armada obtuvo una nueva y definitiva victoria en la batalla naval de Micala.
\end{abstract}
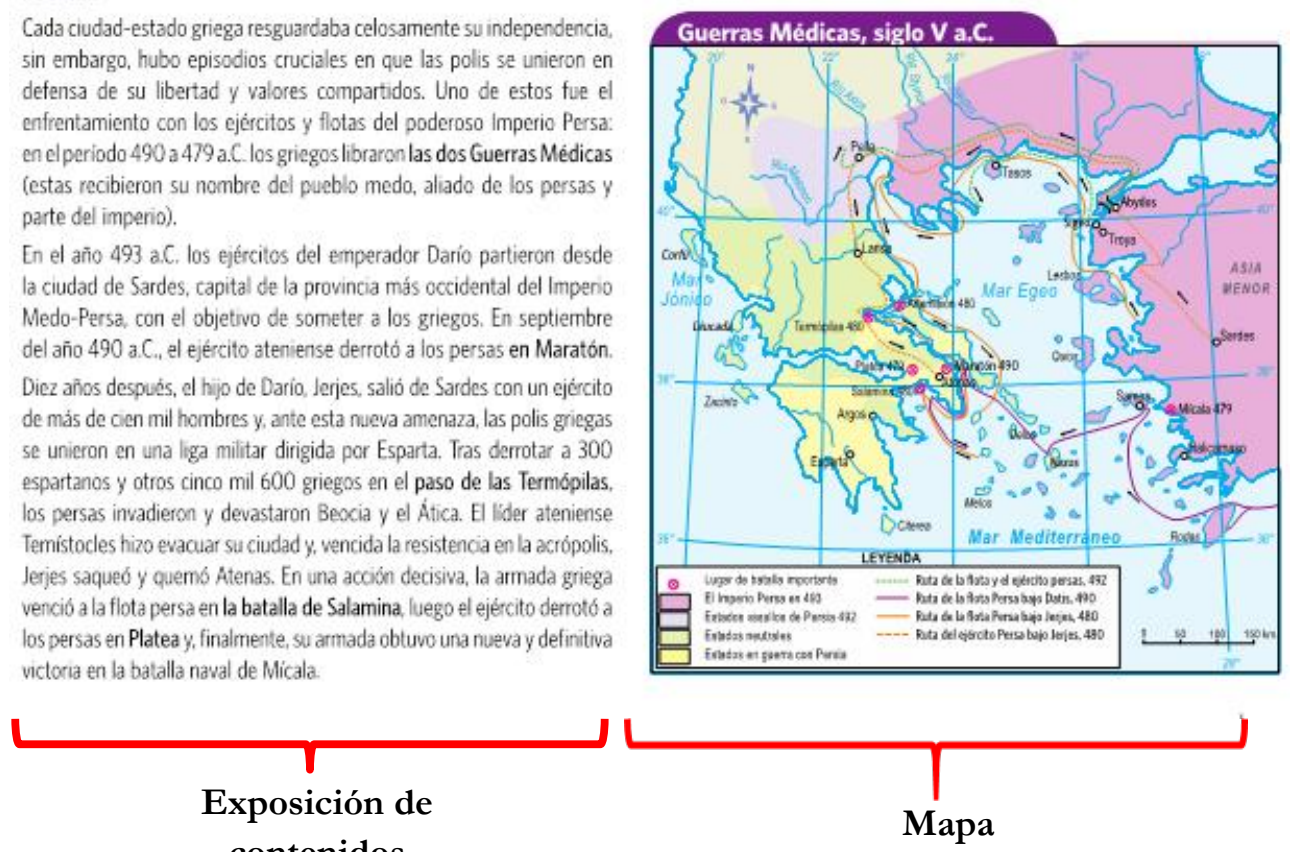

Función: Presentar contenidos disciplinares centrales de una unidad o lección

Función: Facilitar la comprensión de un contenido disciplinar

\section{*AGRADECIMIENTO}

Este artículo fue escrito gracias al financiamiento del proyecto Fondecyt 1160094. 